\title{
Beeporter: tools for high-throughput analyses of pollinator-virus infections
}

\author{
Jay Evans ${ }^{1}$, Olubukola Banmeke ${ }^{2}$, Evan Palmer-Young ${ }^{2}$, Yanping Chen ${ }^{2}$, and Eugene \\ Ryabov $^{2}$ \\ ${ }^{1}$ USDA-ARS Beltsville Bee Research Laboratory, Building 306,10300 Baltimore Avenue, \\ Beltsville, Maryland \\ ${ }^{2}$ USDA-ARS Northeast Area
}

April 19, 2021

\begin{abstract}
Pollinators are in decline thanks to the combined stresses of disease, pesticides, habitat loss, and climate. Honey bees face numerous pests and pathogens but arguably none are as devastating as Deformed wing virus (DWV). Understanding hostpathogen interactions and virulence of DWV in honey bees is slowed by the lack of cost-effective high-throughput screening methods for viral infection. Currently, analysis of virus infection in bees and their colonies is tedious, requiring a well-equipped molecular biology laboratory and the use of hazardous chemicals. Here we describe cDNA clones of DWV tagged with green fluorescent protein (GFP) or nanoluciferase (nLuc), providing high-throughput detection and quantification of virus infections. GFP fluorescence is recorded non-invasively in living bees via commonly available long-wave UV light sources and a smartphone camera or a standard ultraviolet transilluminator gel imaging system. Nonlethal monitoring with GFP allows high-throughput screening and serves as a direct breeding tool for identifying honey bee parents with increased antivirus resistance. Expression using the nLuc reporter strongly correlates with virus infection levels and is especially sensitive. Using multiple reporters, it is also possible to visualize competition, differential virulence, and host tissue targeting by co-occuring pathogens. Finally, it is possible to directly assess the risk of cross-species 'spillover' from honey bees to other pollinators and vice versa.
\end{abstract}

\section{Hosted file}

Evans_Beeporter-MolecEcologyRes_Final.pdf available at https://authorea.com/users/408731/ articles/518628-beeporter-tools-for-high-throughput-analyses-of-pollinator-virusinfections 